\title{
Effect of UBM Thickness on the Mean Time to Failure of Flip-Chip Solder Joints under Electromigration
}

\author{
Y.L. LIN,$^{1}$ Y.S. LAI, ${ }^{2}$ Y.W. $L I N,{ }^{3}$ and C.R. $\mathrm{KAO}^{3,4}$ \\ 1.-Department of Chemical \& Materials Engineering, National Central University, Jhongli \\ City, Taiwan. 2.-Advanced Semiconductor Engineering, Inc., Kaohsiung City, Taiwan. \\ 3.-Department of Materials Science and Engineering, National Taiwan University, Taipei, \\ Taiwan. 4.—e-mail: crkao@ntu.edu.tw
}

Flip-chip solder joints with $\mathrm{Cu} / \mathrm{Ni} / \mathrm{Al}$ underbump metallurgy (UBM) on the chip and an $\mathrm{Au} / \mathrm{Ni}$ surface finish on the substrate were studied under current stressing at an ambient temperature of $150^{\circ} \mathrm{C}$. Three different Ni thicknesses in the $\mathrm{Cu} / \mathrm{Ni} / \mathrm{Al} \mathrm{UBM}(0.3,0.5$, and $0.8 \mu \mathrm{m})$ were used in order to investigate the effect of the Ni thickness on reliability. The solder used was eutectic $\mathrm{Pb}-\mathrm{Sn}$, and the applied current density was $5 \times 10^{3} \mathrm{~A} / \mathrm{cm}^{2}$. The results show that the combined effect of current crowding and the local Joule heating near the entry points of electrons into the joints induced asymmetric Ni UBM consumption. Once the $\mathrm{Ni}$ was exhausted in a certain region, this region became nonconductive and the flow of electrons was diverted to the neighboring region. This neighboring region then became the place where electrons entered the joint, and the Ni UBM there was consumed at an accelerated rate. This process repeated itself, and the Ni-depleted region continued to extend, creating an ever larger nonconductive region. The solder joints eventually failed when the nonconductive region extended across the entire contact window of the joints. This failure model supports the observation that joints with a thicker $\mathrm{Ni}$ tend to have a longer average lifetime.

Key words: Flip chip, electromigration, solder

\section{INTRODUCTION}

As flip-chip solder joints become smaller, the joints have to endure an ever higher current density. Because of this increase, failures caused by electromigration become a real reliability concern. ${ }^{1-9}$ Depending on the experimental conditions, such as the temperature, current density, UBM, and surface finish design, and circuit design, several failure mechanisms have been identified, including void formation and propagation, ${ }^{10,11}$ the local melting mechanism, ${ }^{12}$ and the UBM dissolution mechanism. ${ }^{13,14}$ Recently, it was pointed out that the asymmetrical consumption of the Ni layer in UBM could also caused failures. ${ }^{15,16}$ To extend the lifetime of those solder joints that are prone to fail through the asymmetrical consumption of the Ni layer, the

(Received March 13, 2007; accepted August 24, 2007;

published online: September 26, 2007) use of a thicker Ni UBM layer is a logical avenue. Nevertheless, there is no published report to verify this strategy. In this study, we focus on the effect of Ni UBM thickness on the lifetime of flip-chip solder joints. Specifically, three different $\mathrm{Ni}$ thicknesses, $0.3,0.5$, and $0.8 \mu \mathrm{m}$, were used to study the effect of $\mathrm{Ni}$ thickness on the mean time to failure (MTTF) of flip-chip solder joints under current stressing.

\section{EXPERIMENTAL}

The test chips had a daisy-chained circuit and were mounted on substrates. The solder joints had the configuration illustrated schematically in Fig. 1. The chips had $\mathrm{Al}$ interconnect lines, which were $60 \mu \mathrm{m}$ wide and $1 \mu \mathrm{m}$ thick. The diameter of the contact window was $90 \mu \mathrm{m}$. The UBM on the chips had a $\mathrm{Cu} / \mathrm{Ni} / \mathrm{Al}$ structure. The $\mathrm{Cu}(0.8 \mu \mathrm{m})$ and the $\mathrm{Ni}$ layers were sputter-deposited. Three different Ni 


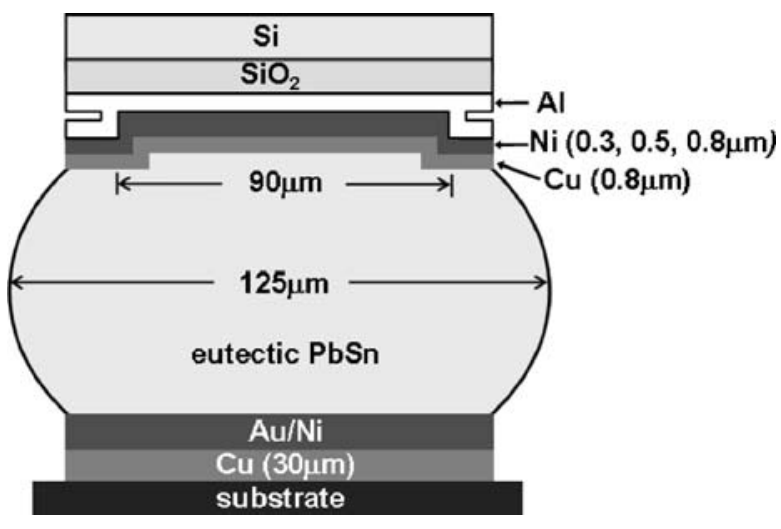

Fig. 1. Schematic showing the solder joint configuration used in this study.

thicknesses, $0.3,0.5$, and $0.8 \mu \mathrm{m}$, were used. On the substrate side, the $\mathrm{Au} / \mathrm{Ni}$ surface finish was used, and the surface finish had $0.1 \mu \mathrm{m} \mathrm{Au}$ and $5 \mu \mathrm{m} \mathrm{Ni}$. The solder was $63 \mathrm{Sn}-37 \mathrm{~Pb}$ eutectic solder, and the solder joints had a nominal diameter of $125 \mu \mathrm{m}$.

During the electromigration test, the assembled chips and substrates were kept in an oven set at $150^{\circ} \mathrm{C}$. A constant $0.32 \mathrm{~A}$ current was passed through the solder joints, producing a nominal current density of $5 \times 10^{3} \mathrm{~A} / \mathrm{cm}^{2}$ (based on the opening area of the contact window). Resistance changes were monitored every $10 \mathrm{~s}$ during the current stressing, and the failure time was determined by an abrupt potential increase in the potentialtime curve. Each value of the MTTF was determined based on 22 test samples.

After different periods of current stressing time, some of the solder joints were cross-sectioned through the middle of the contact window, and examined using a filed-emission scanning electron microscope (FE-SEM). Furthermore, the compositions of the intermetallic compounds were determined by electron probe microanalysis (EPMA).

The distribution of the current density in a solder joint, including the UBM, was simulated by a finiteelement model. The parameters used in simulation are summarized in Table I. In this study, we focused the simulation on the location where the current crowding was the highest, i.e., the entrance of electrons from the $\mathrm{Al}$ interconnects into the joints.

Table I. Values of the Resistivity of the Materials Used in the Current Density Distribution Simulation

\begin{tabular}{lc}
\hline Material & Resistivity $(\mathbf{\Omega} \mathbf{~ c m})$ \\
$\mathrm{Al}$ line & $4.3 \times 10^{-6}$ \\
$\mathrm{Ni}(\mathrm{V})$ & $6.3 \times 10^{-5}$ \\
$63 \mathrm{Sn}-37 \mathrm{~Pb}$ & $1.5 \times 10^{-5}$ \\
$\mathrm{Ni}$ & $6.8 \times 10^{-6}$ \\
$\mathrm{Cu}$ & $1.7 \times 10^{-6}$ \\
\hline
\end{tabular}

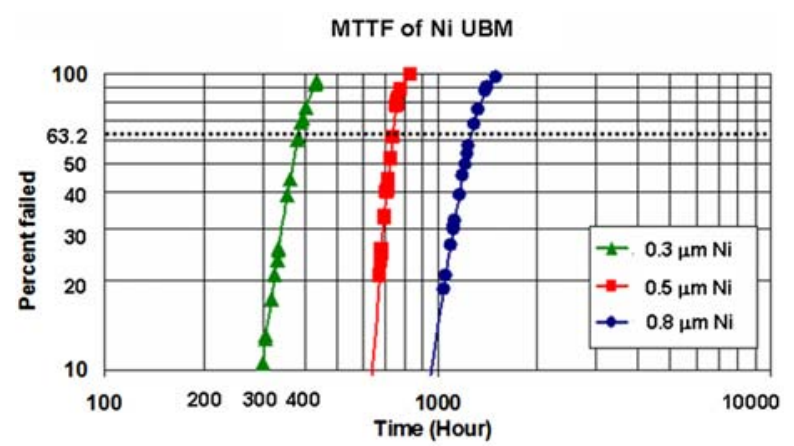

Fig. 2. Weibull plots of the cumulative failure of samples with different Ni thicknesses.

\section{RESULTS}

Figure 2 shows Weibull plots of the samples with different Ni UBM thicknesses. The MTTF of the solder joints were determined to be 384, 736, and $1,269 \mathrm{~h}$ for the $0.3,0.5$, and $0.8 \mu \mathrm{m}$ Ni thicknesses, respectively. The MTTF values reported here are based on 22 samples for each Ni thickness. The MTTF results clearly show that a thicker Ni UBM had a longer lifetime. It is very surprising that the Ni UBM thickness alone was able to produce such a huge performance gain even though everything else was kept the same. In the following, the results from the microstructure examination at different periods of current stressing are presented to gain insight into the failure mechanism and to understand this strong effect of UBM thickness.

\section{Microstructure Evolution under Electromi- gration}

Figure 3 shows the typical microstructures of the solder joints with $0.3 \mu \mathrm{m} \mathrm{Ni}$ that had went through different stages of current stressing. The $0.8 \mu \mathrm{m} \mathrm{Cu}$ layer in the $\mathrm{Cu} / \mathrm{Ni} / \mathrm{Al} \mathrm{UBM}$ had been completely consumed and was converted into $\mathrm{Cu}_{6} \mathrm{Sn}_{5}$ during the assembly of the joint, as had been reported in our previous studies. ${ }^{15,16}$ The $\mathrm{Au}$ layer of the $\mathrm{Au} / \mathrm{Ni}$ surface finish had also been replaced by a $\left(\mathrm{Cu}_{1-x}\right.$ $\left.\mathrm{Ni}_{x}\right)_{6} \mathrm{Sn}_{5}$ layer after assembly. ${ }^{15,16}$ The coarsening of the $\mathrm{Pb}$-Sn eutectic structure with time can be seen in Fig. 3a-c. Figure $4 \mathrm{a}-\mathrm{c}$ are higher-magnification micrographs of Fig. 3a-c, respectively, showing the interfaces near the UBM. After $150 \mathrm{~h}$ of current stressing, as shown in Fig. $4 \mathrm{a}$, the $\mathrm{Cu}_{6} \mathrm{Sn}_{5}$ near the upper-right corner of the joint had become $\left(\mathrm{Cu}_{1-x} \mathrm{Ni}_{x}\right)_{6}$ $\mathrm{Sn}_{5}$, but elsewhere on the chip side no Ni could be detected inside the $\mathrm{Cu}_{6} \mathrm{Sn}_{5}$. After $300 \mathrm{~h}$ of current stressing, as shown in Fig. $4 \mathrm{~b}$, all the $\mathrm{Cu}_{6} \mathrm{Sn}_{5}$ had become $\left(\mathrm{Cu}_{1-x} \mathrm{Ni}_{x}\right)_{6} \mathrm{Sn}_{5}$. Meanwhile, a continuous layer of the $\mathrm{Pb}$-rich phase accumulated on the substrate side of the joint, as shown in Fig. 3b. This showed that $\mathrm{Pb}$ was the main migration species. This result is expected because at $150^{\circ} \mathrm{C} \mathrm{Pb}$ diffuses faster than Sn. ${ }^{17}$ After $400 \mathrm{~h}$ of current stressing, as 

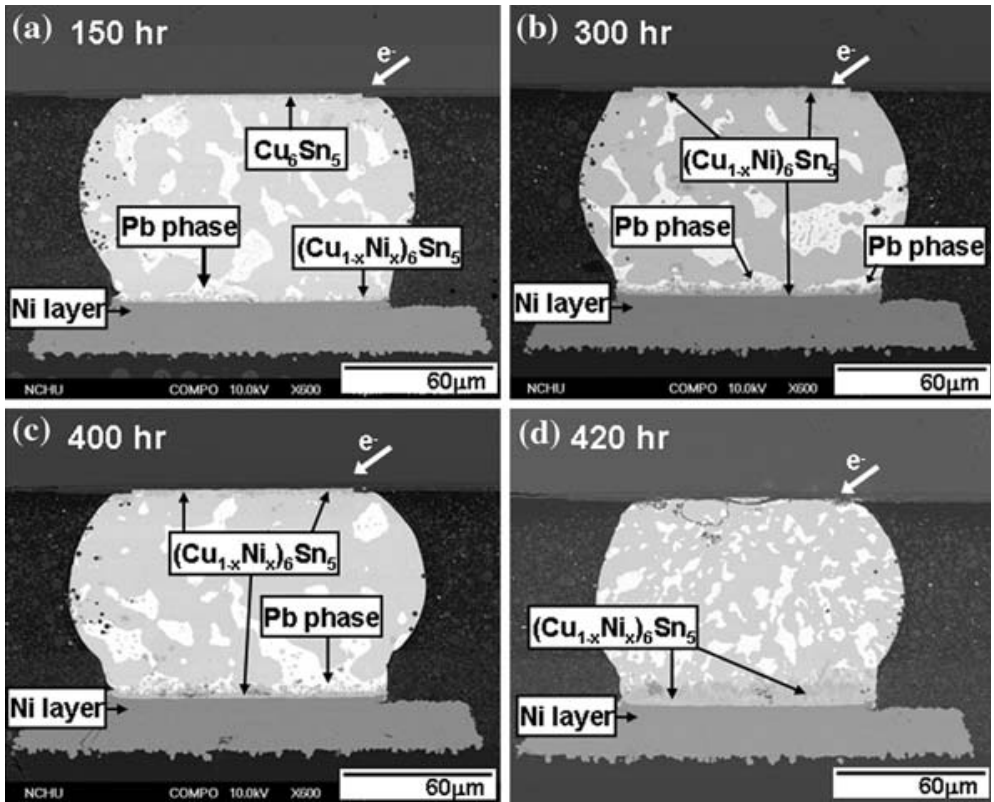

Fig. 3. Microstructures of the joints with $0.3 \mu \mathrm{m} \mathrm{Ni}$ that had been stressed at $150^{\circ} \mathrm{C}$ for (a) 150 , (b) 300 , (c) 400 , and (d) $420 \mathrm{~h}$. The electrons entered the joints from the upper-right corner.
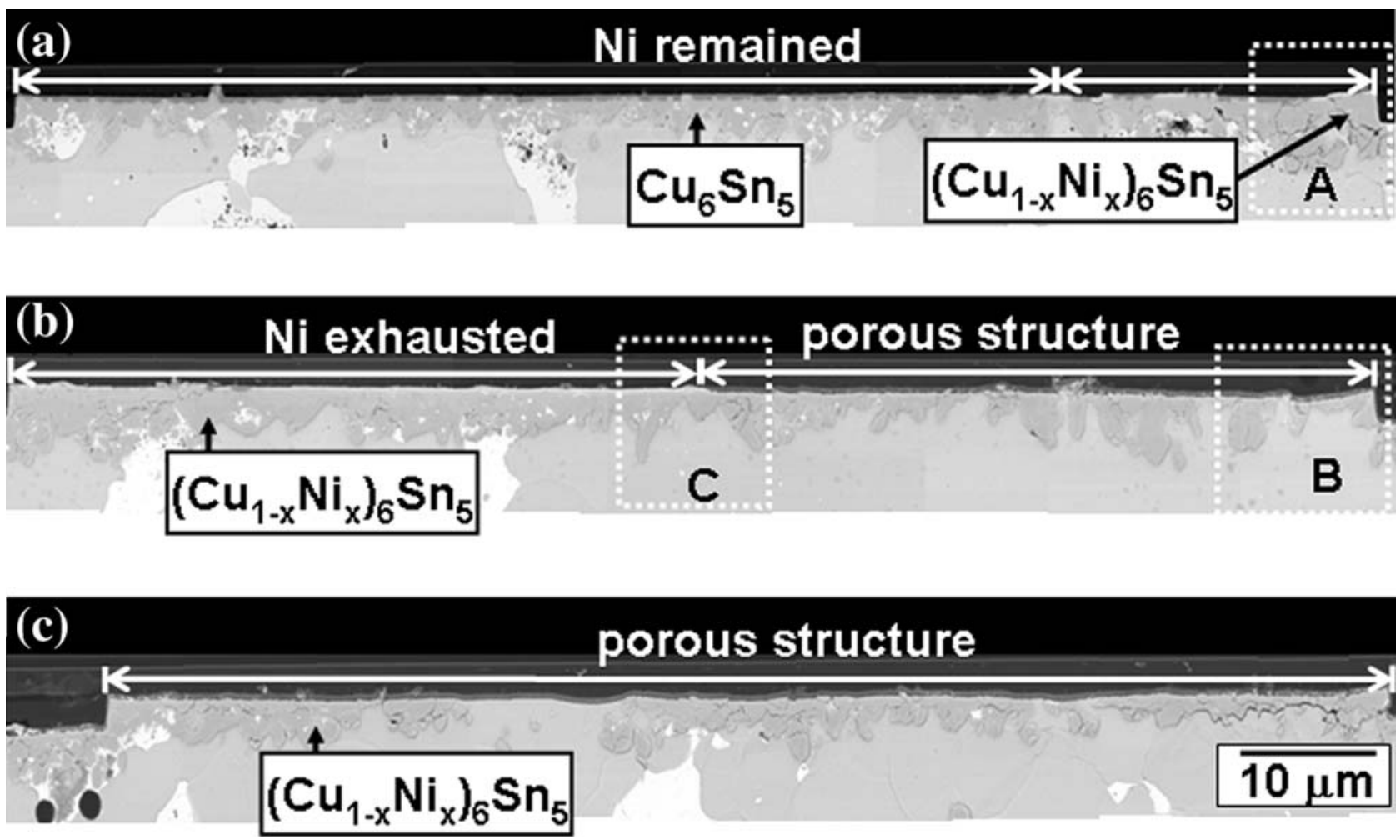

Fig. 4. (a) Higher-magnification micrograph for the UBM region of Fig. 3a. This micrograph is a composite picture from several micrographs that have a smaller field of view. (b) Higher-magnification micrograph for the UBM region of Fig. 3b. (c) Higher-magnification micrograph for the UBM region of Fig. 3c.

shown in Fig. 4c, no void occurred in the solder joint even though the MTTF value (384 h) suggested that it was about to fail. The joint failed at $420 \mathrm{~h}$, as shown in Fig. 3d. The coarsened $\mathrm{Pb}-\mathrm{Sn}$ eutectic structure was replaced by a finer one, suggesting that the entire joint had melted at failure. Figure $3 d$ also shows that no electromigration-induced void can be seen in the solder. 


\section{Ni UBM Consumption and the Porous Structure}

Figure 4a shows that only the part of the Ni UBM near the entrance for the electrons had been consumed. Meanwhile, the Ni UBM at other location was still intact. No $\mathrm{Ni}$ could be detected in this $\mathrm{Cu}_{6} \mathrm{Sn}_{5}$ beneath the intact $\mathrm{Ni}$ UBM. When the stressing time reached $300 \mathrm{~h}$, all the Ni UBM had been completely consumed and $\mathrm{Ni}$ could be detected in all the $\left(\mathrm{Cu}_{1-x} \mathrm{Ni}_{x}\right)_{6} \mathrm{Sn}_{5}$, as shown in Fig. $4 \mathrm{~b}$. The simultaneous disappearance of the Ni layer and the appearance of $\mathrm{Ni}$ in the $\left(\mathrm{Cu}_{1-x} \mathrm{Ni}_{x}\right)_{6} \mathrm{Sn}_{5}$ suggests that the dissolution of $\mathrm{Ni}$ into $\mathrm{Cu}_{6} \mathrm{Sn}_{5}$ was the main consumption mechanism for the Ni layer. At this stage, the so-called porous structure ${ }^{15,16}$ was limited to the right-hand side of the UBM, but after $400 \mathrm{~h}$ of current stressing, as shown in Fig. 4c, the porous structure had extended across the entire UBM.

Shown in Fig. 5a-c are the higher-magnification micrographs for the $\mathrm{A}, \mathrm{B}$, and $\mathrm{C}$ regions in Fig. 4, respectively. It is clearly visible that the Ni UBM consumption initiated at the upper-right corner, as shown in Fig. 5a. No void formed at the interface. Figure 5b shows that the Ni UBM had been completed replaced by the porous structure. The leading edge of the porous structure is shown in Fig. 5c. Summarizing the features in Fig. 5a-c, one notes that the Ni consumption and the formation of the porous structure was a sequence of events that initiated at the right-hand side and extended to the left under current stressing.

\section{DISCUSSION}

\section{The Effect of Current Crowding and Joule Heating}

It had been reported that current crowding effect plays an important role in the reliability of flip-chip solder joints under electromigration. ${ }^{1-7,10,11,13}$ In order to understand the degree of current crowding, a three-dimensional finite-element simulation was used to calculate the current density distribution of the joint. Figure 6 a shows the mesh geometry used in this study. Figure $6 \mathrm{~b}-\mathrm{d}$ shows the simulated current density distribution for $0.3,0.5$, and $0.8 \mu \mathrm{m}$ $\mathrm{Ni}$ UBM joints, respectively. Although the average current density was $5 \times 10^{3} \mathrm{~A} / \mathrm{cm}^{2}$ based on the neck of the contact window, the simulation shows that the highest current density in Fig. $6 \mathrm{~b}-\mathrm{d}$ can be as high as $6.3 \times 10^{5}, 6.1 \times 10^{5}$, and $4.4 \times 10^{5} \mathrm{~A} / \mathrm{cm}^{2}$, respectively. The peak current density decreased from $6.3 \times 10^{5}$ to $4.4 \times 10^{5}$ as the Ni UBM thickness increased from $0.3 \mu \mathrm{m}$ to $0.8 \mu \mathrm{m}$. This was because thicker UBM could effectively spread out the passing electrons. The results in Fig. $6 \mathrm{~b}-\mathrm{d}$ show that the peak current density here was 100 times higher than that of the average current density. This extreme local current density would cause an excessive local Joule heating, which in turn caused a higher local temperature at the Ni UBM. This
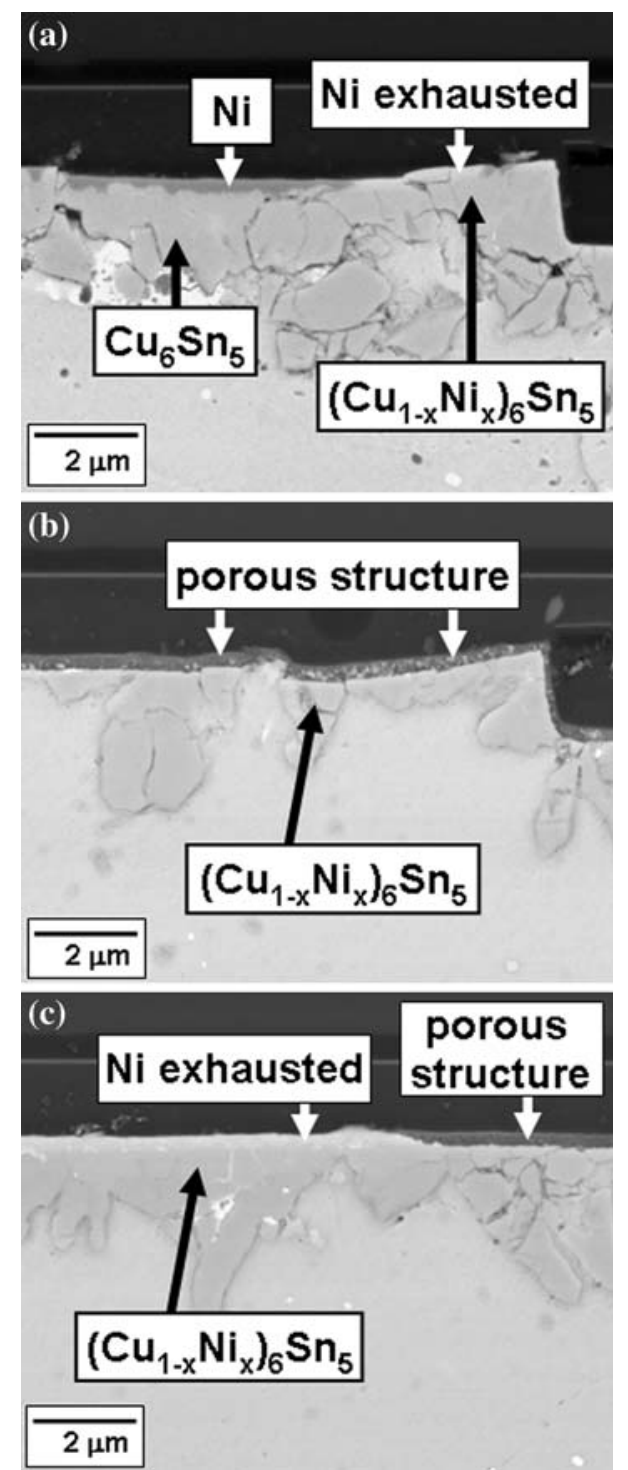

Fig. 5. (a) Higher-magnification micrograph of region A in Fig. 4a. (b) Higher-magnification micrograph of region $B$ in Fig. $4 b$. (c) Higher-magnification micrograph of region $\mathrm{C}$ in Fig. $4 \mathrm{~b}$.

high local temperature combined with the high local electromigration, which was caused by the high local current density, accelerated the local interfacial reaction and diffusion between the solder and the Ni UBM layer. Consequently, the Ni UBM consumption rate would be faster near the highcurrent-density region.

In this study, local accelerated $\mathrm{Ni}$ consumption was indeed observed, as shown in Fig. 5a. It was clearly visible that the local Ni UBM near the entrance of electrons had been exhausted and replaced by the intermetallic compound. This suggested that the thin Ni layer was locally consumed before the formation of the voids near the region with the peak current density.

The porous structure observed in this study is similar in appearance to the porous structure observed in the reaction between the phased-in 


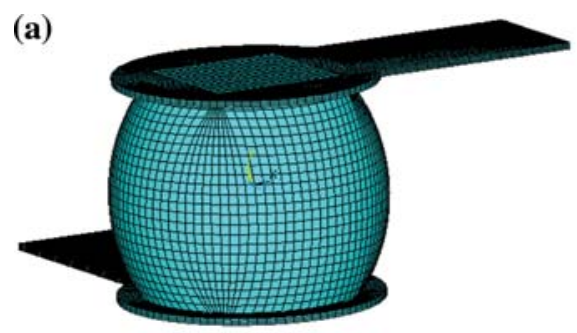

(b)

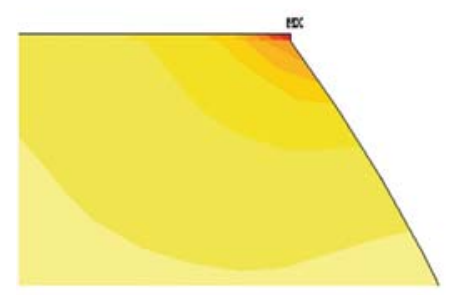

(c)

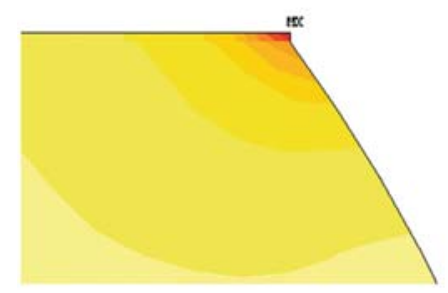

(d)
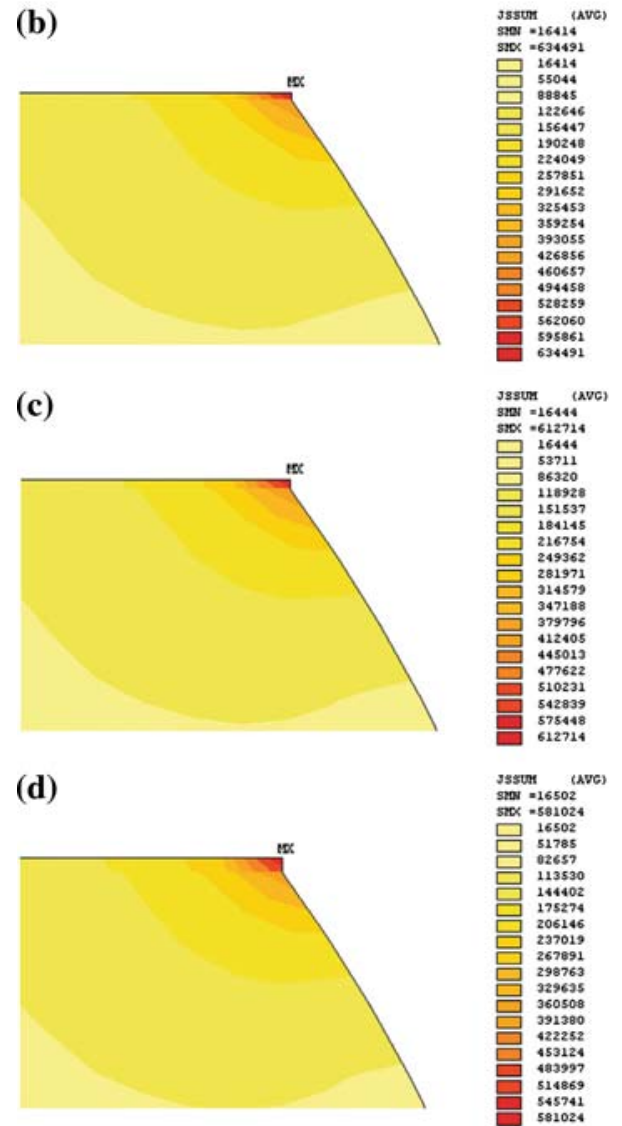

Fig. 6. (a) Meshes of the finite-element model used in this study. (b) Calculated current density distribution for $0.3 \mu \mathrm{m}$ Ni UBM. (c) Calculated current density distribution for $0.5 \mu \mathrm{m}$ Ni UBM. (d) Calculated current density distribution for $0.8 \mu \mathrm{m} \mathrm{Ni} \mathrm{UBM}$.

$\mathrm{Cu}-\mathrm{Cr}$ UBM and solder. ${ }^{18}$ It was commented that the porous layer might have a high electrical resistance. ${ }^{18}$ In other words, the porous structure resulting from the reaction between $\mathrm{Cu}-\mathrm{Cr}$ and solder might also have the ability to divert the electrons.

\section{Failure Mechanism and the MTTF}

The void formation and propagation mechanism was reported to be a major failure mechanism under several different stressing conditions..$^{2,3,10-12}$ In this mechanism, a void forms in the solder at the location with the highest local current density, and the electrons are diverted around the void, making the solder next to the edge of the void become the highest current density region. This causes the void to grow toward the region with the highest current density.
This process repeats itself, and the void gradually propagates until an open circuit is created. However, in this study, the role of the void was replaced by the porous structure, which presumably was nonconductive. Once the porous structure formed, the electrons were diverted to nearby region, causing the porous structure to extend toward that region. The joints failed when the porous structure extended all the way across the joint. In the void formation and propagation mechanism, one key factor determining the MTTF is the incubation time for void nucleation. ${ }^{11}$ Once the void nucleates, its propagation can cause the joint to fail very quickly. In the $\mathrm{Ni}$ UBM consumption mechanism observed in this study, the key factor determining the MTTF was the time required to consume a certain thickness of the Ni UBM. As can be seen in Fig. 2, the thicker the Ni UBM, the longer the MTTF.

Void formation and propagation and $\mathrm{Ni}$ UBM consumption are competing mechanisms. If a void nucleates before the Ni UBM is consumed, void formation and propagation will be the dominant mechanism. Conversely, if the Ni UBM is consumed before the void nucleates, Ni UBM consumption will be the dominant mechanism. If the UBM design and the materials used are kept the same, the stressing conditions, which include the applied current density, the environmental temperature, the heat dissipation capacity of the package, and the chip/ package circuit design, which determines the amount of Joule heating, will determine the dominant mechanism.

\section{SUMMARY}

It was found that the combined effect of higher local current density and the resulting local Joule heating in Ni UBM was able to produce locally accelerated Ni consumption. Once the Ni UBM was exhausted at a location, a porous structure formed. As this structure was nonconductive, the electrons were diverted to the neighboring region where $\mathrm{Ni}$ UBM was still intact. This process repeated itself and eventually the porous structure extended across the entire contact window, causing the joint to fail. For the solder joints that failed according to this mechanism, a thicker Ni UBM was able to increase the MTTF. This study found that the MTTF for the solder joints with $0.3,0.5$, and $0.8 \mu \mathrm{m} \mathrm{Ni}$ UBM were 384,736 , and $1,269 \mathrm{~h}$, respectively.

The role of the porous structure in the Ni UBM consumption mechanism was similar to the role played by the void in the void formation and propagation mechanism in that they were both nonconductive and could divert the electrons to nearby regions. The diverted electrons then caused the porous structure or the void to extend toward the new high-current-density region. These two mechanisms competed with each other, and the final failure mechanism depended on the chip/package design and the stressing conditions. 


\section{ACKNOWLEDGEMENT}

This work was supported by the National Science Council of the R.O.C. through Grant NSC-95-2221E-002-441.

\section{REFERENCES}

1. C.Y. Liu, K.N. Tu, T.T. Sheng, C.H. Tung, D.R. Frear, and P. Elenius, J. Appl. Phys. 87, 750 (2000).

2. W.J. Choi, E.C.C. Yeh, and K.N. Tu, J. Appl. Phys. 94, 5665 (2003).

3. Y.C. Hsu, T.L. Shao, C.J. Yang, and C. Chen, J. Electron. Mater. 32, 1222 (2003).

4. H. Ye, C. Basaran, and D. Hopkins, Appl. Phys. Lett. 82, 1045 (2003).

5. M. Lu, T.L. Shao, C.J. Yang, and C. Chen, J. Mater. Res. 19 2394 (2004).

6. T.L. Shao, S.W. Liang, T.C. Lin, and C. Chen, J. Appl. Phys. 98, 044509 (2005).

7. H. Gan and K.N. Tu, J. Appl. Phys. 97, 063514 (2005).

8. S. Gee, L. Nguyen, L. Zhang, S. Ou, J. Huang, and K.N. Tu, Appl. Phys. Lett. 88, 012106 (2006).
9. C.M. Tsai, Y.S. Lai, Y.L. Lin, C.W. Chang, and C.R. Kao, J. Electron. Mater. 35, 1781 (2006).

10. E.C.C. Yeh, W.J. Choi, K.N. Tu, P. Elenius, and H. Balkan, Appl. Phys. Lett. 80, 580 (2002).

11. Y.H. Lin, Y.C. Hu, C.M. Tsai, C.R. Kao, and K.N. Tu, Acta Mater. 53, 2029 (2005).

12. C.M. Tsai, Y.L. Lin, J.Y. Tsai, Y.S. Lai, and C.R. Kao, J. Electron. Mater. 35, 1005 (2006).

13. Y.C. Hu, Y.H. Lin, C.R. Kao, and K.N. Tu, J. Mater. Res. 18, 2544 (2003).

14. Y.H. Lin, C.M. Tsai, Y.C. Hu, Y.L. Lin, and C.R. Kao, J. Electron. Mater. 34, 27 (2005).

15. Y.L. Lin, C.W. Chang, C.M. Tsai, C.W. Lee, and C.R. Kao, J. Electron. Mater. 35, 1010 (2006).

16. Y.L. Lin, Y.S. Lai, C.M. Tsai, and C.R. Kao, J. Electron. Mater. 35, 2147 (2006).

17. D. Gupta, K. Vieregge, and W. Gust, Acta Mater. 47, 5 (1999).

18. T.K. Hooghan, S. Nakahara, K. Hooghan, R.W. Privette, M.A. Bachman, and R.S. Moyer, Thin Solid Films 437, 235 (2003). 